\title{
ANALISIS KONSTRUKSI PIPA POMPA SUCTION 112-JB
}

\author{
Pungkas Satria \\ Departemen Teknik Mesin, \\ Universitas Diponegoro \\ pungkassatriast@gmail.com
}

\author{
Achmad Widodo \\ Departemen Teknik Mesin, \\ Universitas Diponegoro \\ awidodo2010@gmail.com
}

\author{
Ismoyo Haryanto \\ Departemen Teknik Mesin, \\ Universitas Diponegoro \\ ismoyo2001@yahoo.de
}

\author{
Djoeli Satrijo \\ Departemen Teknik Mesin, \\ Universitas Diponegoro \\ djoeli_satrijo@yahoo.com
}

\author{
Budi Setiyana \\ Departemen Teknik Mesin, \\ Universitas Diponegoro \\ bsetiyana@yahoo.com
}

\begin{abstract}
The 101-JTC condenser tank has excess steam condensate due to the addition of admission steam from 101-JT. Therefore, it is necessary to design a piping system that connects 101-JTC condenser tank with the 112-JB pump to drain the condensed excess steam. The designed piping system will encounter a dynamic response caused by fluid flow fluctuation over the time. This dynamic response causes the pipe to experience stress. To find out the resulting voltage which will not cause damage or failure, it is necessary to estimate the safety factor in a piping system that has been given static and dynamic loading. This research uses the fluid structure interaction or FSI method with the help of ANSYS software as a simulation tool. The results of this study are, the flow in the pipe causes an impact load which makes the structure vibrate freely damped. The resulting dynamic response describes, the structure displacement amplitude decreases with increasing time. This indicates a stable vibration. Finally, when viewed from the value of stress against time, the fatigue that occurs in the pipe structure induce a stress below the stress limit on Goodman diagram. It can be estimated that the structure has no service life limit. The fatigue safety factor is 7.1.
\end{abstract}

Keyword: pipe system, safety factor, structure, fluid flow

\section{LATAR BELAKANG}

Tangki kondensor 101-JTC memiliki kelebihan condensed steam yang diakibatkan oleh penambahan admission steam dari 101-JT. Hal ini menyebabkan tangki kondensor 101-JTC mengalami kegagalan karena melebihi kapasitas penyimpanan condensed steam. Oleh karena itu, dibutuhkan rancangan sistem perpipaan yang menyambungkan tangki kondesor 101-JTC dengan pompa 112-JB untuk mengalirkan kelebihan condensed steam. Sistem perpipaan dalam suatu pabrik merupakan bagian terpenting untuk menghubungkan komponen-komponen pabrik dengan mengalirkan fluida dari satu komponen ke komponen lainnya [1] Sistem perpipaan terdiri dari bagian-bagian pipa yang memiliki fungsi spesifik [2]. Sistem perpipaan adalah cara yang paling umum dan murah dalam memindahkan fluida dari satu titik pemrosesan ke titik yang lain. Oleh karena itu, pabrik selalu menggunakan sistem perpipaan sebagai konstruksi utama [3]. Rancangan suatu sistem perpipaan harus mampu menahan semua beban yang terjadi, baik beban konstan maupun beban fluktuatif sebagai fungsi waktu. Berdasarkan hal tersebut perlu dilakukan analisis konstruksi untuk memastikan bahwa sistem perpipaan mampu menahan beban sehingga bekerja dengan aman [4]. Tanpa analisis konstruksi maka akan ada potensi kebocoran pada sambungan, kerusakaan, dan distorsi pada komponen sistem perpipaan lainnya, termasuk komponen yang terhubung ke tangki kondensor dan sisi hisap pompa [5]. Sistem perpipaan memiliki standar yang telah ditentukan oleh American Society of Mechanical Engineering (ASME) [6]. Pada pabrik, digunakan standar ASME B 31.3 (process piping) dalam merancang dan memilih komponen sistem perpipaan [7]. Nilai tegangan pada rancangan sistem perpipaan yaitu tegangan yang disebabkan oleh berbagai beban harus memenuhi standar keamanan dan tidak boleh melebihi tegangan luluh dari material pipa. Hal tersebut harus diperhatikan agar tidak mengalami kegagalan [8]. Apabila tegangan yang terjadi melebihi tegangan ijin sesuai kode standar ASME B 31.3 maka akan terjadi perubahan bentuk pipa yang dapt menyebabkan kegagalan [9]. Pembebanan dinamis diketahui melalui pendekatan fluid structure interaction (FSI). FSI adalah penting untuk memastikan masalah dari aliran yang menyebabkan getaran. Hal ini dapat menyebabkan terlepasnya sistem perpipaan dari mekanisme tumpuan seperti penggantung dan balok penyangga, serta meningkatkan resiko kerusakan pada sistem perpipaan tersebut. Pengaruh aliran fluida pada struktur perpipaan tergantung dengan karakteristik fluida, komposisi, massa jenis, viskositas, dan turbulensinya [10]. Dalam penelitian ini, rancangan sistem perpipaan 112-JB telah ditentukan melalui survey lokasi. Rancangan sistem perpipaan membutuhkan perkiraan tegangan yang disebabkan oleh pembebanan statis dan dinamis, agar memiliki faktor keamanan yang sesuai. Penentuan perkiraan tegangan tersebut dilakukan menggunakan perangkat lunak melalui permodelan dan simulasi 
computational fluid dynamics (CFD) dan finite element methods (FEM). Permodelan dan simulasi dengan bantuan komputer tersebut menghasilkan nilai perkiraan tegangan rancangan sistem perpipaan 112-JB yang akurat dan memiliki nilai yang komprehensif [11]. Penjelasan lebih detalinya, sistem perpipaan akan mengalami respon dinamis yang disebabkan oleh aliran fluida yang berfluktuasi terhadap waktu. Respon dinamis tersebut menyebabkan pipa mengalami tegangan. Untuk mengetahui berapa tegangan yang dihasilkan agar tidak menyebabkan kerusakan atau kegagalan maka perlu perkiraan factor keamanan (safety factor) pada sistem perpipaan tersebut.

\section{METODE PENELITIAN}

Gambar 1 menunjukkan diagram alir simulasi untuk menganalisis pengaruh pembebanan dinamis dan statis.

Penelitian dimulai dengan pembuatan geometri menggunakan ANSYS SPACECLAIM. Dasar pembuatan geometri adalah gambar isometrik dari sistem perpipaan untuk pompa 112-JB dan ASME B31.3. Simulasi dilakukan dua kali simulasi yaitu 1) simulasi computational fluid dynamics (CFD) untuk mengetahui tekanan pada fluida, 2) simulasi finite element methods (FEM) untuk mengetahui tegangan yang disebabkan oleh beban pipa, dan komponen pipa. Simulasi kedua menggunakan hasil dari simulasi pertama sebagai imported load.

Proses meshing terhadap fluid domain, dilakukan dengan memberikan fungsi sizing dimana ukuran pada setiap element yang dihasilkan sebesar $50 \mathrm{~mm}$ dan fungsi inflasi untuk mendapatkan profil kecepatan alir yang lebih baik. Proses meshing menghasilkan 77.119 nodal dan 18.236. Fungsi sizing elemen dilakukan pada structure domain, dimana size pada setiap elemen yang dihasilkan sebesar $45 \mathrm{~mm}$. Selanjutnya khusus pada support, ukuran setiap elemen adalah $25 \mathrm{~mm}$. Hasil meshing berupa 130.194 nodal dan 18.776 elemen.

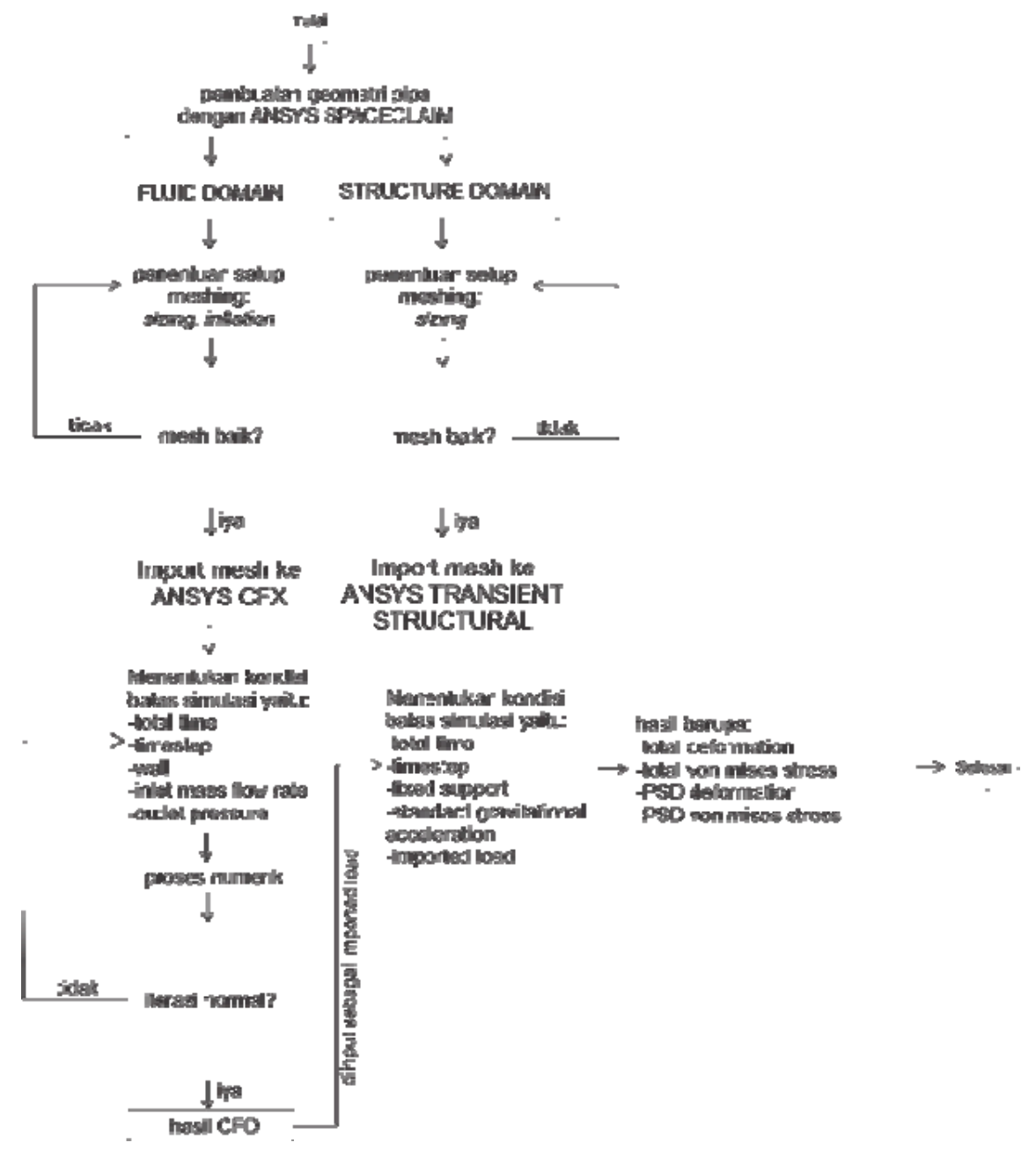

Gambar 1. Diagram alir penelitian. 
Penentuan kondisi batas pada domain fluida dilakukan setelah meshing, kemudian hasilnya diekspor ke ANSYS CFX. Berikutnya ditentukan pengaturan solusi (setting solver) dimana fluida bergerak dengan fungsi waktu. Parameter pengaturan pada solver settings dijelaskan pada Tabel 1.

Tabel 1. Setting solver pada ANSYS CFX

\begin{tabular}{ll}
\hline Solver settings & Settings used \\
\hline Analysis Type & Transient \\
\hline Total Time & $10 \mathrm{~s}$ \\
\hline Time step & $0.01 \mathrm{~s}$ \\
\hline Material type & Water vapor at $25^{\circ} \mathrm{C}$ \\
\hline Turbulence type & k-epsilon \\
\hline Wall & No-slip wall \\
\hline
\end{tabular}

Langkah selanjutnya penentuan kondisi syarat batas dimana inlet memiliki mass flow rate sebesar 0.023 $\mathrm{kg} / \mathrm{s}$ dan kondisi batas outlet yaitu pressure outlet sebesar $0 \mathrm{MPa}$.

Masukan untuk structure domain adalah beban pada setiap komponen pipa, terdiri dari beban valve yaitu $144 \mathrm{~kg}$, beban strainer $96 \mathrm{~kg}$, beban expansion joint $36,38 \mathrm{~kg}$, dan fixed support yang diletakan di bagian ujung pipa. Selanjutnya dimasukkan nilai percepatan gravitasi sebesar $9,81 \mathrm{~m} /$ detik $^{2}$ dan penentuan permukaan imported load, hasil dari simulasi CFD.

Material yang digunakan pada analisis ini adalah structural steel dan water vapor. Material structural steel digunakan pada struktur pipa sedangkan water vapor untuk fluida yang mengalir di dalam struktur pipa tersebut. Sifat material diperoleh dari ANSYS 18.2 engineering data sebagaimana ditunjukkan pada Tabel 2 .

Tabel 2. Data sifat material pipa.

\begin{tabular}{lc}
\hline \multicolumn{2}{c}{ Structural Steel } \\
\hline Density & $7850 \mathrm{~kg} / \mathrm{m}^{3}$ \\
\hline Young's Modulus & $2 \mathrm{E}+11 \mathrm{~Pa}$ \\
\hline Poisson's ratio & 0,3 \\
\hline Tensile Yield Strength & $2,5 \mathrm{E}+11 \mathrm{~Pa}$ \\
\hline Tensile Ultimate Strength & $4,6 \mathrm{E}+8 \mathrm{~Pa}$ \\
\hline $\begin{array}{l}\text { Mass-Matrix Damping } \\
\text { Multiplier }\end{array}$ & 12,56 \\
\hline $\begin{array}{l}\text { K- Matrix Damping } \\
\text { multipier }\end{array}$ & 0,003 \\
\hline
\end{tabular}

Untuk menentukan kegagalan yang disebabkan oleh kelelahan pada material, diperlukan diagram $S$ $N$ curve. Titik alternating stress dan mean stress, dibawah diagram Goodman yang ditentukan oleh endurance stress dan ultimate tensile strength. Gambar 2 menunjukkan diagram $S-N$ curve untuk material structural steel.

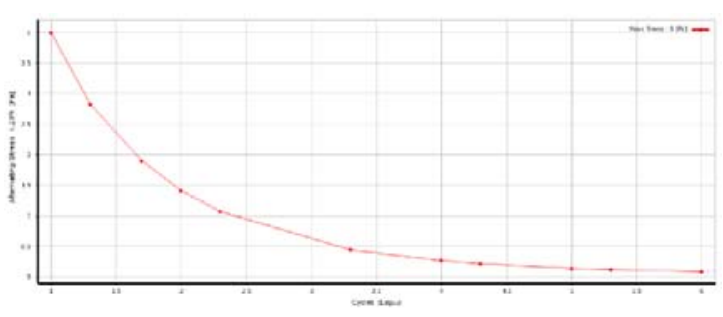

Gambar 2. S-N curve untuk structural steel.

\section{HASIL DAN PEMBAHASAN Hasil Analisis Modal}

Hasil output perpindahan pada analisis modal, tidak dapat didefinisikan sebagai nilai perpindahan total dari sistem perpipaan yang dirancang, namun hasil perpindahan di setiap modus getar (mode shape). Hal ini menjelaskan orientasi dan letak getaran yang akan terjadi. Sementara itu, nilai frekuensi adalah hasil perkiraan frekuensi pribadi. Tabel 3 menunjukan hasil dari analisis modus getar.

Tabel 3. Frekuensi pribadi sistem

\begin{tabular}{cc}
\hline Modus & Frekuensi $(\mathrm{Hz})$ \\
\hline 1 & 8,7196 \\
\hline 2 & 15,374 \\
\hline 3 & 33,543 \\
\hline 4 & 35,368 \\
\hline 5 & 42,563 \\
\hline 6 & 58,287 \\
\hline
\end{tabular}

Modus shape yang dihasilkan pada frekuensi tersebut dapat diperlihatkan pada gambar 3 .
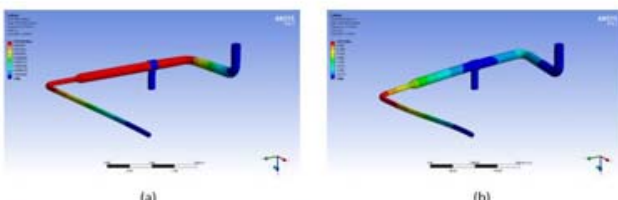

(a)
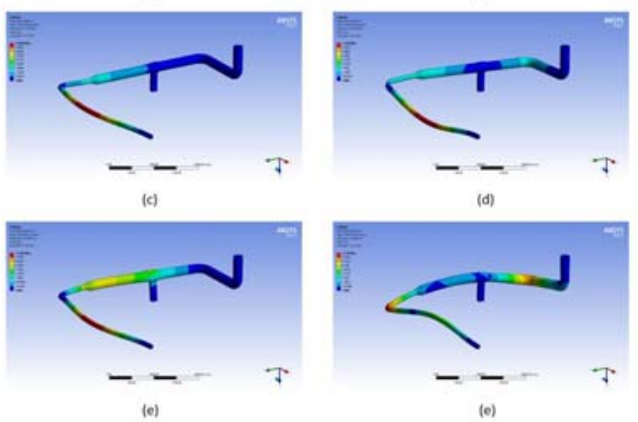

Gambar 3. Modus shape untuk frekuensi pribadi sistem: a) modus 1, b) modus 2 , c) modus 3 ,

d) modus 4, e) modus 5, f) modus 6 .

Hasil dari analisis modal berfungsi untuk verifikasi nilai getaran yang terjadi pada analisis struktur. 


\section{Hasil Simulasi CFD}

Salah satu luaran hasil simulasi CFD adalah plot tekanan terhadap waktu. Luaran ini diperoleh dengan cara mendefinisikan titik pada wall. Titik tersebut ditentukan dengan mempertimbangkan aliran yang mengalami vortex. Aliran hasil simulasi CFD dapat dilihat pada profil streamline yang ditunjukan pada Gambar 4

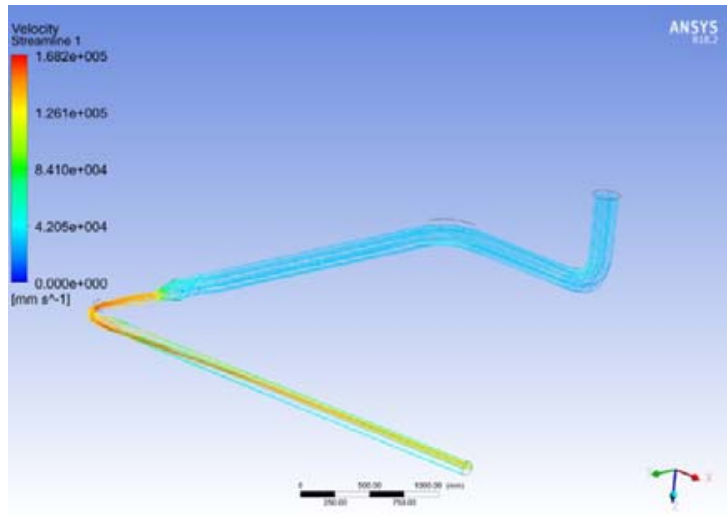

Gambar 4. Profil streamline kecepatan alir.

Aliran terlihat mengalami vortex pada bagian sebelum reducer. Bagian tersebut diperiksa lewat luaran plot tekanan terhadap waktu. Hasil plot dapat dilihat pada Gambar 5.

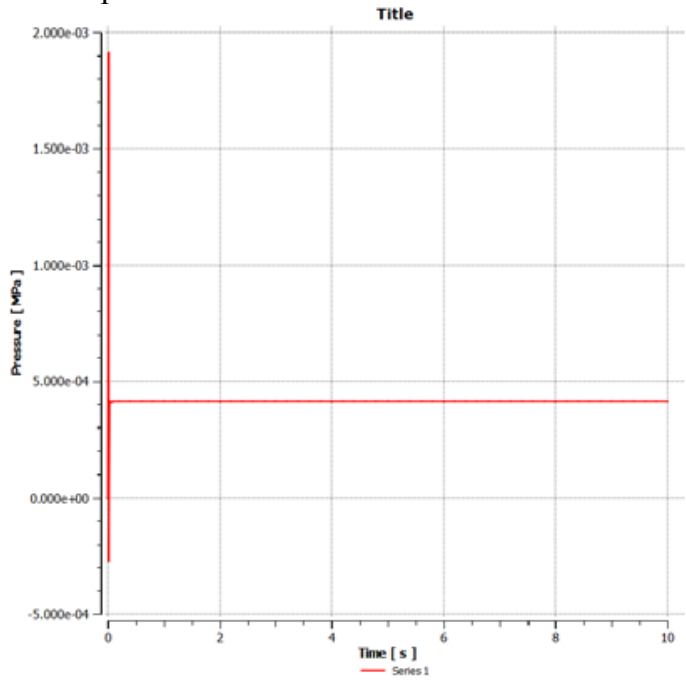

Gambar 5. Plot tekanan terhadap waktu pada rentang 0-10 detik.

Dapat dijelaskan bahwa fluida mengalami impulse pada detik-detik awal sehingga tekanan menjadi tinggi. Aliran mengalami osilasi setelah impulse. Plot ini berfungsi untuk menunjukan karakteristik getaran yang terjadi pada fluida.

\section{Hasil Simulasi Finite Element Methods}

Hasil simulasi CFD digunakan sebagai imported load untuk FEM. Letak imported load didefinisikan pada dinding dalam pipa. Hasil CFD kemudian diinterpolasi ke dalam struktur domain. Hasil imported load dapat dilihat pada Gambar 6.

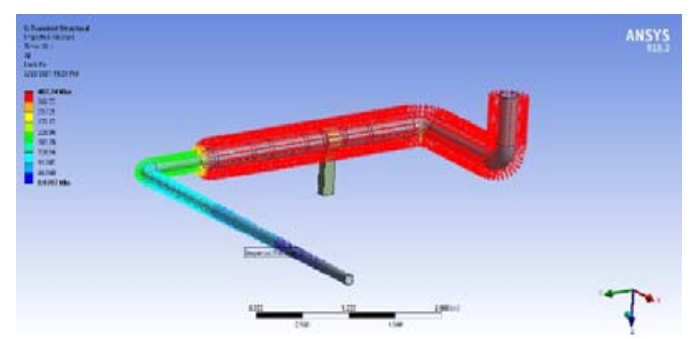

Gambar 6. Hasil imported load.

Setelah semua kondisi batas ditentukan, proses numerik dilakukan untuk menghasilkan perpindahan total, total equivalent stress, power spectral density (PSD), dan fatigue. Nilai hasil perpindahan total, ditunjukan pada Gambar 7.

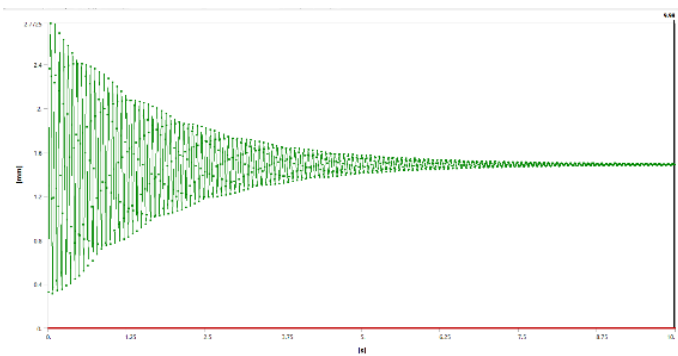

Gambar 7. Grafik displacement terhadap waktu.

Berdasarkan plot tersebut terlihat bahwa perpindahan maksimum sebesar $2,77 \mathrm{~mm}$ terjadi pada waktu 0,04 detik. Gambar 7 juga menunjukkan bahwa semakin lama durasi sistem, semakin kecil perpindahan yang terjadi pada pipa. Hal ini menandakan adanya redaman getaran yang disebabkan oleh material pipa. Daerah perpindahan tertinggi terjadi pada lekungan pipa 4 inchi.

Gambar 8 menunjukkan nilai tegangan total yang dinyatakan dengan plot tegangan sebagai fungsi waktu.

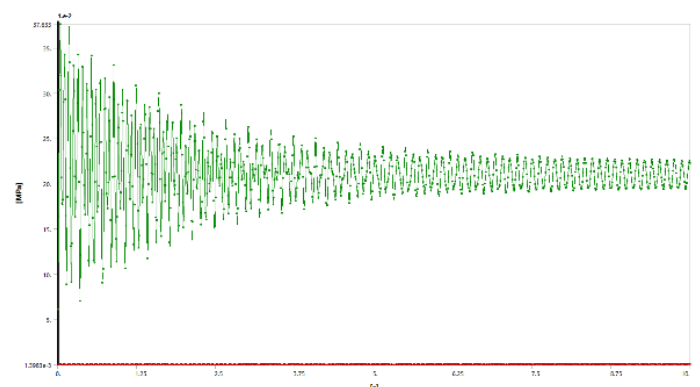

Gambar 8. Plot tegangan terhadap waktu.

Berdasarkan gambar tersebut nampak bahwa tegangan maksimum sebesar $37,633 \mathrm{MPa}$ pada waktu 0,04 detik. Selanjutnya, tegangan yang terjadi 
mengalami penurunan seiring berjalannya waktu. Namun demikian, nilai tegangan terus berosilasi. Tegangan maksimum terjadi di daerah tumpuan.

\section{Kriteria Lelah Goodman}

Kelelahan pada material yang disebabkan oleh fluktuasi tegangan dapat dilihat dengan kriteria Goodman pada structural steel, dimana fatigue limit, $S_{e}$, sebesar $169 \mathrm{MPa}$ dan ultimate tensile strength, $S_{u t}$ sebesar $460 \mathrm{MPa}$. Berikutnya pada hasil pembebanan dinamis yaitu nilai tegangan terhadap waktu, memiliki nilai alternating stress, $\sigma_{a}$ sebesar $15,75 \mathrm{MPa}$ dan mean stress, $\sigma_{m}$, sebesar 21,19 MPa. Kriteria Goodman dapat dilihat pada Gambar 9.

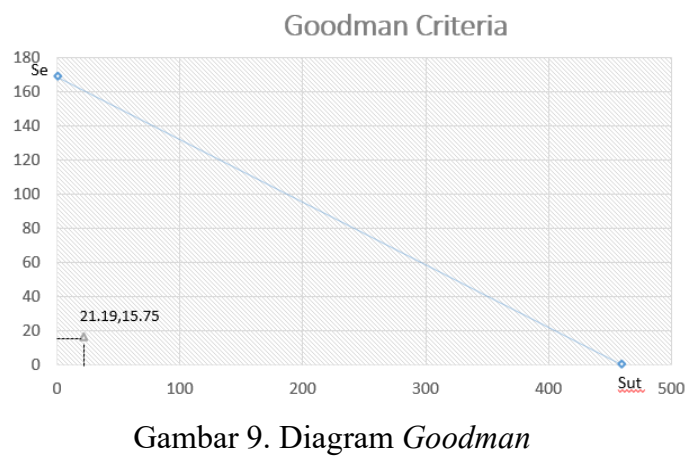

Hasil simulasi pembebanan statis maupun dinamis tidak melewati kriteria Goodman pada material structural steel. Nilai fatigue safety factor sebesar 7,1 yang berarti aman.

\section{KESIMPULAN}

Aliran dalam pipa menyebabkan impulse sehingga struktur mengalami getaran paksa. Hasil respon dinamis menunjukkan bahwa amplitudo displacement struktur menurun seiring dengan bertambahnya waktu. Hal ini menandakan bahwa getaran stabil dan tidak mengalami resonansi.

Kelelahan yang terjadi pada struktur pipa, apabila ditinjau dari nilai tegangan terhadap waktu, menunjukkan bahwa tegangan tersebut tidak melebihi batas pada diagram Goodman. Struktur diperkiraan aman, tidak memiliki batas umur pemakaian dan memiliki nilai faktor keamanan sebesar 7.1 .

\section{PENELITAN LANJUTAN}

Penelitian lanjutan perlu dilakukan dengan variasi posisi tumpuan pada struktur pipa dan variasi nilai mass flow rate pada simulasi CFD. Jumlah titik plot tekanan terhadap waktu, dan plot PSD akan ditambah.

\section{REFERENSI}

[1] Mahardika, P., 2017, "Penentuan Allowable Span Antar Penyangga Pipa SLF
Berdasarkan Tegangan, Defleksi, Frekuensi Alami”, Jurnal Iptek 21(2), pp. 27-34.

[2] Firdaus, H. H., dan Satrijo, D., 2017, "Perancangan dan Analisa Sistem Perpipaan Process Plant Dengan Metode Elemen Hingga", Jurnal Teknik Mesin 2(4), pp. 487496.

[3] Rohmah, S. M., Chamsudi, A., Soetijono, A. 2017, "Analisa Tegangan Sistem Perpipaan Air Fin Cooler Pada Project Petrochemical Complex PT Trans Pasific Petrochemical Indotama-Tuban", Tugas Akhir Mahasiswa FMIPA, ITS.

[4] American Society Of Mechanical Engineering, 2006, "ASME B 31.3 Process Piping”, ASME, New York.

[5] Mahardhika, P., 2018, "Analisa Pengaruh Kenaikan Tekanan Fluida Terhadap Tegangan dan Fleksibilitas Pipa Blowdown A106 Grade A Berdasarkan ASME B31.3", Teknik, 39(1), pp. 67-77.

[6] Salifu, S.A., 2019, "Thermo-Mechanical Stress Simulation of Unconstrained Region of Straight X20 Steam Pipe", Proc. Manufacturing 35, pp. 1330-1336.

[7] Husodo, A. W., Mahardhika, P., Viqqi Vadilla, V. A., 2019, “Analisa Fleksibilitas Sistem Perpipaan Pada Fatty Acid Plant Akibat Pergeseran Posisi Evaporator", Jurnal Integrasi 11(2), pp. 112-118.

[8] Yusuf, M. R., Heroe Poernomo, H., Abul Gafur, A. 2017, “Analisa Tegangan Sistem Perpipaan Line BTF-PJUTIPCTP-PI-DW005 ORF (Onshore Receiving Facility) Akibat Soil Settlement", Proc. of $4^{\text {th }}$ Conf. Piping Engineering and Its Appl., Program Studi D4 Teknik Perkapalan, Politeknik Perkapalan Negeri Surabaya.

[9] Haryono, S., Purwadi, M. D., Basori., 2014), "Analisis Tegangan Sistem Perpipaan Minyak Pada Sisi Hisap Pompa Dengan Perangkat Lunak Caesar II", Jurnal Sains dan Teknologi Indonesia 16(2), pp. 28-38.

[10] Balakrishnan, S.,. Veerappan, A.R., Shanmugam, S. 2019, "B2 stress index for structurally distorted pipe bends under inplane opening bending moment", Intl. J. Pressure Vessels and Piping 176, 103957.

[11] Ahn, M.Y., Cho, S., Lee, E. H., Park, Y.-H., Lee, Y., 2016 "Pipe stress analysis on HCCR-TBS ancillary systems in conceptual design", Fusion Engineering and Design 109-111(Part B), pp. 1169-1173.

[12] Raafat, E., Nassef, A., Medhat El-hadek, M., El-Megharbel, A. 2019, "Fatigue and thermal stress analysis of submerged steel pipes using ANSYS software", Ocean Engineering 193, 106574 